\title{
Air passenger movements and economic growth in Sri Lanka: Co-integration and causality analysis
}

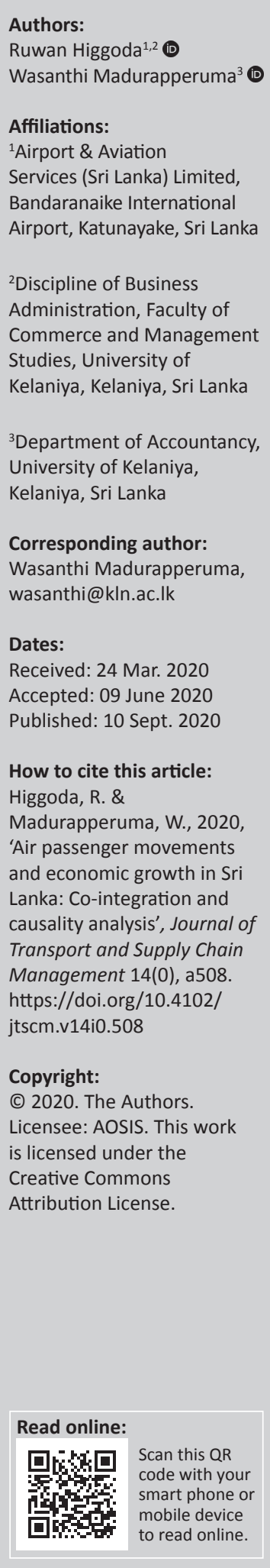

Background: It is generally recognised that air passenger transport contributes to the economic growth in developed and developing countries. Hence, air transportation is used as a policy instrument for stimulating economic growth. Air transport contributes to the economic welfare of the nation and long-term economic growth throughout trade and tourism. However, relatively little attention has been devoted to this phenomenon.

Objectives: The aim of this research article was to investigate the aviation-centric growth hypothesis for Sri Lanka by testing causation between aviation and economic growth.

Method: Using time series data over a period of 37 years (1983-2019), this study employed Johansen cointegration test methods, followed by Granger's causality tests.

Results: The results of this study confirm that there is no long-run relationship between air transportation and economic growth in Sri Lanka. However, the results show that there is a short-run unidirectional Granger causality, which runs from economic growth to total passenger movements.

Conclusion: It can be concluded from the findings that they disprove the aviation-centric growth hypothesis and instead suggest that air transport does not play a significant role in the promotion of Sri Lanka's economic growth. Furthermore, the existence of unidirectional causality from economic growth to air transport and the recognised time lags of 2-3 years would guide government and policymakers to manage resources properly and allocate resources efficiently for the sectors, which accelerate economic growth in Sri Lanka.

Keywords: aviation; economic growth; unit root tests; air transportation; vector auto-regression; impulse response.

\section{Introduction}

Economic activities from both the production and supply aspect and the consumption and demand aspect highly depend on the transportation sector. This dependence has evolved since the ancient times where the role of transport in transporting human beings (services) and goods has become increasingly important. This article analyses 'aviation and/or air travel' as a covariate in the relationship with the economic growth of a country. Recent studies, for example, Brida, Rodríguez Brindis and Zapata-Aguirre 2016, Fernandes and Rodrigues Pacheco (2010) and Kasim and Mahmut (2019) have discussed this issue, and many others (Brida et al. 2016; Marazzo, Scherre \& Fernandes 2010; Mehmood, Khan and Khan 2012) have shown positive impacts of air transportation on economic growth of a country. However, no attention is given to an empirical analysis of the relationship between economic growth and air transportation in Sri Lanka, which justified the purpose of this research. The main aim of this research is to explore and investigate the causal relationship between air transportation and economic growth in Sri Lanka. To measure air transportation, this study employs 'total passenger movements' (TPM) and to measure economic growth, gross domestic production (GDP) in constant prices is used. Econometric tests such as unit root tests and test of cointegration proposed by Johansen (1988) are used as mathematical analysis tools and techniques. The time duration covered by the research study is from 1983 to 2019. This article examines the relationship between air transportation and economic growth by employing the Johansen cointegration approach for the long run and the standard vector auto-regression (VAR) method for the short run. This article contributes to the existing methodology in Brida et al. (2014) and Marazzo et al. (2010) to estimate cointegration equations. 
The structure of this article is as follows. Firstly, literature review is presented in the next section, followed by the research methodology of the study. Then the empirical studies that have utilised cointegration and causality methods to analyse causal relationship between air transportation and economic growth are introduced. Finally, conclusions and recommendations for future studies are made.

\section{Literature review}

Empirical work on aviation-led economic growth is still in its infancy. Few existing literature is available. The World Bank Report (2018) discusses the development of the air transport sector in Sri Lanka during the period 2010-2015. According to the report, the aviation sector has shown positive performance from 2010, with the end of 30 years of civil war, and the economic impact of the aviation sector is expected to grow in next 20 years. The total number of arrivals in 2016 under aircraft movements was recorded as 33684 with more than 5.4 million passengers and the total number departures was recorded as 33667 with more than 5.4 million passengers. Cargo movements were above 100000 metric tons in both imports and exports and the overflying movements were approximately 40000 . The aviation industry reflects an intense growth during 2010-2018 in all three sectors and it is preojected to grow rapidly in next five years. In terms of spending, the aviation industry, including its supply chain, is assessed to contribute $\$ 446$ million of the GDP in Sri Lanka. Expenditure by international tourists contributed a further $\$ 7.4$ billion to the country's GDP, adding $\$ 7.9 \mathrm{bn}$. Altogether, $8.9 \%$ of the country's GDP is reinforced by contributions to the air transport sector. Many economists have stated that the absence of air travel and connectivity can discourage the growth and economy capability. This argument is mainly supported by the economies of the United States of America, China, Germany, India, the United Arab Emirates and Japan. These economies have strong, effective and productive aviation industries and ultimately these economies are either the most developed or fastest growing economies in the world (Bourguignon \& Darpeix 2016).

Marazzo et al. (2010) have conducted an inventive research study on aviation-growth relationship, where they theoretically examined the connection between aviation demand and GDP of Brazil. They employed passengerkilometre as a representation of aviation demand and found a long-run equilibrium between the two variables using bivariate Vector Autoregressive Model. The study results reflected strong positive relationship between GDP, demand of aviation travel, and the considerably weaker interconnection the other way round. Robustness tests were employed through the Hodrick-Prescott's filter to attain the cyclical apparatuses of the series and the results endured these robustness tests.

Kasım and Mahmut (2019) investigated the relationship between air transportation and economic development based on high-income, upper middle-income, lower middle income and low-income-level countries. Focusing on the period 1990-2016, a total of 70 countries were classified according to their levels of income and were analysed empirically, and the study found that GDP has a certain degree of effect on air transport. The study also indicated that the unidirectional or bidirectional causal relationships running from GDP to air transport and air transport to GDP vary by the income level of the countries. Accordingly, there is a direct causal relationship between GDP and air transport in Australia, Austria, Iceland, Netherlands, New Zealand, the United Arab Emirates and the United Kingdom. In addition, in Ireland, there is a causal relationship between air transport and GDP. In Italy, there is a bidirectional causality running from GDP to air transport as well as from air transport to GDP. The Fisher test statistic results show that high-income countries have a unidirectional causal relationship running from GDP to air transport. The results further indicate a unidirectional causal relationship running from GDP to air transport in Argentina, Costa Rica, Ecuador and Lebanon. Furthermore, in Brazil and Romania, there is a bidirectional causal relationship running from GDP to air transport as well as from air transport to GDP. In Turkey, there is a causal relationship running from air transport to GDP. For the upper-middle-income countries, the Fisher test statistics point to the presence of a causal relationship running from GDP to air transport at the $1 \%$ level of significance, and from air transport to GDP at the 5\% significance level.

Mehmood and Kiani (2013) explored the aviation-led growth hypothesis for Pakistan by analysing Granger causality between air travel and economic development using statistical analysis including unit root tests and cointegration tests. Using the data from the period 1973-2012, they transformed the work of Marazzo et al. (2010) by applying fully modified ordinary least squared (OLS) method and dynamic OLS for the estimation of cointegration equation. Their estimation showed that a positive involvement of air travel demand to economy is more prominent than that of economic growth to aviation demand. They found that the positive contribution of aviation demand to economic development is related in both fully modified OLS and dynamic OLS methods.

Nisansala and Mudunkotuwa (2015) presented that there is a bidirectional (GDP $\leftrightarrow$ AT) long-run causal relationship between GDP and air transportation. According to the literature, no further instances of research on the Sri Lankan aviation industry exist.

This study is aimed to expand and strengthen previous studies on the relationship between air transport and economic growth. Therefore, this study contributes to the existing empirical literature on the causal relationship between air transportation and economic growth. To significantly add to empirical literature, this article focuses on analysing the aviation-led growth connection for Sri Lanka. For this purpose, data dimensions and sources are explained in the next section. 


\section{Research methodology}

According to Marazzo et al. (2010), the demand for aviation is characterised by 'total passenger movement' and the economic growth is measured by GDP in local currency (at constant terms). Data for these variables are taken from a credible source, such as the Central Bank of Sri Lanka and Airport \& Aviation (SL) Limited. In the analysis, all data were expressed logarithmically in order to include the proliferative effect of time series. Annual data from 1983 to 2019 were used for our empirical investigation. The time period enabled us to use 36 observations for our time series analysis. EViews version 8 software program was used for all estimations; before performing the inferential analysis, line chart and descriptive analysis were developed. To measure the relationship between economic growth (GDP) and total air passenger movement (TPM), we adopted a generic regression equation as follows:

$\mathrm{GDPt}=\mathrm{f}\left(\mathrm{TPM}_{\mathrm{t}}\right)$

[Eqn 1]

where GDP refers to the economic growth and TPM refers to total passenger movements. In order to minimise the scale effect of number, we express the above relation in linear form using the variables in logarithm:

$\log \mathrm{GDP}_{\mathrm{t}}=\alpha_{\mathrm{i}}+\beta_{1} \log \mathrm{TPM}_{\mathrm{t}}+\varepsilon_{\mathrm{t}}$

where $t=1 \ldots n$ denotes the time period and $\varepsilon_{\mathrm{t}}$ denotes the stochastic error term

\section{Model specification}

In the literature, many empirical studies (Anfofum, Saheed \& Iluno 2015; Baker et al. 2015; Hakim \& Merkert 2016) are devoted to investigate the links between air passenger transport and economic growth. However, there are not many research studies that have investigated or proven the causality of this relationship (Fernandes \& Rodrigues Pacheco 2010). Some studies have shown that there is a bidirectional causality between air transport and economic growth; some other studies have shown that a unidirectional relationship exists between these two variables. The present study contributes to the existing empirical literature on the causal relationship between air transportation and economic growth. Accordingly, this article posits the following hypotheses of causal relationship between air transportation and economic growth as follows:

Hypotheses 1(a):

$\mathrm{H}_{0}$ : Air passenger movement does not cause economic growth.

$\mathrm{H}_{1}$ : Air passenger movement causes economic growth (this is termed the aviation-led growth hypothesis).

\section{Hypotheses 1(b):}

$\mathrm{H}_{0}$ : Economic growth does not cause air passenger movement.

$\mathrm{H}_{1}$ : Economic growth causes air passenger movement (this is termed the growth-led aviation hypothesis).
The researchers utilised the Granger causality approach developed by Engle and Granger (1987) to identify the possible causal relationships between air transportation and economic growth.

\section{Vector Autoregressive Model}

To prove the relative effect of air transportation on economic growth, a reduced form $\operatorname{VAR}(p)$ model is utilised because it is generally used to test the dynamic relationship between economic growth and air transportation. The $\operatorname{VAR}(p)$ model is mostly significant because the variables under study are treated symmetrically in a structural sense. Also variables of air transportation and economic growth under study are viewed as a system of reduced form equations in which each endogenous variable can be regressed on its own lagged values and the lagged values of all other variables in the system (Gujarati 2004).

Subsequently, the reduced VAR model shows each variable as a linear function of its own lag values, the lag values of all other variables, which has been considered, and a serially uncorrelated disturbance term $\left(\varepsilon_{t}\right)$. Therefore, in this study the $\operatorname{VAR}(p)$ model involves two equations: the first is the current economic growth as a function of past (lag) values of economic growth and air transportation; and the second equation is the air transportation as a function of past(lag) values of air transportation and economic growth. Each equation is estimated by employing ordinary least squares regression. A basic $\operatorname{VAR}(p)$ model assumes the following form, where $p$ refers to the number of lags:

$$
\Delta \log \mathrm{GDP}_{t}=\alpha 0+\beta 11 \Delta \log \mathrm{GDP}_{t-p}+\beta 12 \Delta \log \mathrm{TPM}_{t-p}+\varepsilon 1_{t}
$$

[Eqn 3]

$$
\Delta \log \mathrm{TPM}_{t}=\beta 0+\beta 21 \Delta \log \mathrm{GDP}_{t-p}+\beta 22 \Delta \log \mathrm{TPM}_{t-p}+\varepsilon 2_{t}
$$

[Eqn 4]

\section{Unit root}

The VAR model is based on the assumptions of (1) stationarity, (2) that errors are white noise and (3) that the error term is time invariant with a positive definite covariance matrix. The Dickey-Fuller (DF) test is used to test for unit root in first-order autoregressive model, autoregressive (AR) (1), with the basic assumption that errors are white noise. The PhillipsPerron (PP) test is used to confirm serial correlation in the error terms by adding more lag difference terms of the dependent variable. The null hypothesis of the non-stationarity should be tested against the alternative hypothesis of no unit root.

\section{Cointegration test}

The cointegration test is used after assessing the stationarity of the series as unit root tests do not provide a decisive outcome about the order of integration of the variables. Therefore, it is important to check the order of integration before discussing the short-term and long-term relationships 
of variables. Engle and Granger's (1987) two-step procedure and Johansen's (1991) maximum likelihood procedure are the two common tests used for examining cointegration. The determination of the number of cointegrating vectors is usually based on the trace test and the maximum eigenvalue test, both of which are used to determine the existence of long-term relationship between the dependent and the explanatory variables in a multivariate framework. In this study, both tests were utilised. The decision about how many lag orders to be included in the model depends on the lag order selection criterion. Both the Akaike information criterion (AIC) and Bayes information criterion (BIC) are used to choose the optimum lag length, as recommended by Burnham and Anderson (2004).

\section{Granger causality}

In economics, causal directions are possible in macroeconomic variables. The most widely used definition of causality is that the past and present may cause the future but the future cannot cause the past (Granger and Joyeux 1980). The structure of the $\operatorname{VAR}(p)$ model provides information about forecasting the ability of a variable or a group of variables. According to the Granger causality approach, one variable is caused by another. In Equations 3 and 4, a bivariate model, the pattern of causality can be identified by estimating the regression of economic growth (GDP) and air transportation (TPM) on all the relevant variables, including the current and past values of air transportation and economic growth, and by testing the appropriate hypothesis developed in this study.

\section{Impulse response function and variance decomposition}

Furthermore, causal inference, forecasting and diagnosis of the empirical model's dynamic behaviour were tested by employing impulse response functions (IRF) and forecast error variance decomposition (EVD) methods. The IRF method indicates the effects of an exogenous shock on the entire process over time according to Stock and Watson (1993). The key idea is that IRF detects the dynamic relationships amongst contemporaneous values of the variables over time, after an assumed shock in time $t$. This adjustment is compared with the actual time series process. The impulse response sequences plot the variance between two time paths. The EVD method indicates the share of the variance in the forecast error for each variable because of shocks to all variables in the system. In contrast to IRF, EVD is used to obtain information about the forecast ability.

\section{Stability tests}

The diagnostic and stability test for the goodness-of-fit of the VAR equations was conducted. Testing whether the estimated long-run parameters change over time is important because unstable parameters can result in model misspecification, which can potentially bias the results. Hence, for testing the long-run parameter stability in the cointegrating equations, where GDP is the dependent variable, multivariate recursive procedures proposed by Hansen and Johansen $(1993,1999)$ were used to appraise the constancy of both the cointegration space and the loadings of the cointegration vector. The structural stability was examined by means of the cumulative sum (CUSUM) and cumulative sum of squares (CUSUMQ). The CUSUMQ statistics are updated recursively and plotted against the break points. If the plots of the CUSUMQ statistics remain within the $5 \%$ critical bound, the null hypothesis for all coefficients in the given regression is stable and thus cannot be rejected.

\section{Ethical consideration}

This article followed all ethical standards for a research without direct contact with human or animal subjects.

\section{Results and discussion Preview of data}

The aim of this study was to examine the relationship between air transportation and economic growth in Sri Lanka. Economic growth is measured by GDP (current Sri Lankan rupee [LKR]), whilst demand for aviation is measured by 'total (domestic and international) passengers movements (TPM). The line charts of GDP and TPM are illustrated against time period in Figure 1.

Figure 1 shows the link between the performance of economic activity and the number of air passengers. The time series plots of economic growth and TPM show that there is a long-term increasing trend. It indicates that both economic growth and TPM are related over the study period. The result further indicates that some form of nonstationarity and non-linearity exist in the observed data series. Both series show trend and intercepts. These insights will support in performing the stationarity tests.

\section{Descriptive data analysis}

Table 1 provides the descriptive statistics of the data used in this study. When observing the standard deviations, the data show standard deviations of 1.43 and 0.706 for $\log$ (GDP) and

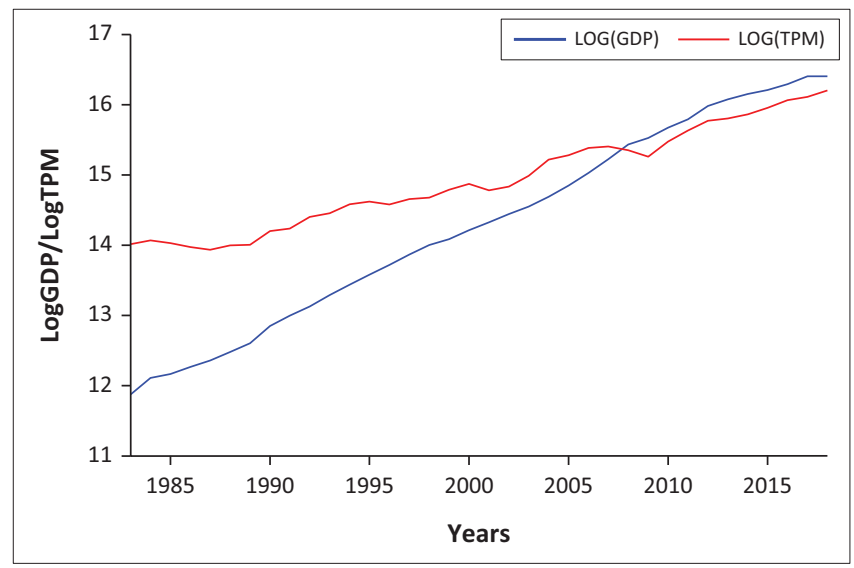

GDP, gross domestic product; TPM, total passengers movements.

FIGURE 1: Real gross domestic product and the number of passengers traveling by air to, from and within Sri Lanka from 1983 to 2019. 
$\log (\mathrm{TPM})$, respectively, although the values are relatively small. This gives us an indication that the mean value of log $\left(\mathrm{GDP}_{\mathrm{t}}\right)$ and $\log \left(\mathrm{TPM}_{\mathrm{t}}\right)$ is relatively close to the true mean of our overall population. Distributions of both variables are positively skewed. The Jarque-Bera normality test rejects the assumption of non-normality for all of the variables.

\section{Correlation analysis}

As shown in Table 1-A1, there is evidence of positive $(\rho+)$ correlation between air passenger transportation and economic growth, with a value of $98 \%$. This may indicate an unambiguous relationship between these two variables but correlations do not imply any causality.

\section{Unit root tests}

Augmented Dickey-Fuller (ADF) and PP tests were used to check the stationarity of the series, and the results are presented in Table 2.

TABLE 1: Descriptive statistics for the sample period.

\begin{tabular}{lcc}
\hline Descriptive measures & LOG(GDP) & LOG(TPM) \\
\hline Mean & 14.28041 & 14.92984 \\
Median & 14.26959 & 14.81129 \\
Maximum & 16.40457 & 16.20253 \\
Minimum & 11.87709 & 13.93361 \\
Std. Dev. & 1.435617 & 0.706627 \\
Skewness & -0.050456 & 0.202572 \\
Kurtosis & 1.736256 & 1.833281 \\
Jarque-Bera & 2.410846 & 2.288062 \\
Probability & 0.299565 & 0.318532 \\
Sum & 514.0948 & 537.4743 \\
Sum Sq. Dev. & 72.13484 & 17.47626 \\
Observations & 36 & 36 \\
\hline
\end{tabular}

GDP, gross domestic production; TPM, total passenger movements; Std. Dev., standard deviation; Sum Sq. Dev, sum of squared deviations.

TABLE 2: Augmented Dickey-Fuller and Phillips-Perron tests.

\begin{tabular}{|c|c|c|c|c|}
\hline $\begin{array}{l}\text { Using constant } \\
\text { and trend }\end{array}$ & Stationarity & Variables & $t$-Statistic & Prob. value \\
\hline \multirow{4}{*}{$\begin{array}{l}\text { Augmented } \\
\text { Dickey-Fuller } \\
\text { (ADF) }\end{array}$} & \multirow[t]{2}{*}{ At level } & GDP & -4.4850 & 0.2672 \\
\hline & & TPM & -3.9575 & 0.3202 \\
\hline & \multirow{2}{*}{$\begin{array}{l}\text { At first } \\
\text { difference }\end{array}$} & $\Delta \mathrm{GDP}$ & -4.9172 & $0.0020 \dagger$ \\
\hline & & $\triangle \mathrm{TPM}$ & -4.9505 & $0.0017 \dagger$ \\
\hline \multirow{4}{*}{$\begin{array}{l}\text { Phillips and } \\
\text { Perron (PP) }\end{array}$} & \multirow[t]{2}{*}{ At level } & GDP & -1.5614 & 0.7872 \\
\hline & & TPM & -2.826 & 0.1978 \\
\hline & \multirow{2}{*}{$\begin{array}{l}\text { At first } \\
\text { difference }\end{array}$} & $\Delta \mathrm{GDP}$ & -4.9531 & $0.0018 \dagger$ \\
\hline & & $\Delta T P M$ & -4.6789 & $0.0007 \dagger$ \\
\hline
\end{tabular}

GDP, gross domestic production; TPM, total passenger movements; Prob. value, probability value.

Note: Augmented Dickey-Fuller and PP tests of GDP express stationarity at first difference with significance at all levels $(1 \%, 5 \%$ and $10 \%)$, whilst that of TPM show stationarity at first difference with significance at $5 \%$ and $10 \%$ levels.

$\dagger$, Rejection of null hypothesis at $5 \%$ level.
Economic growth and air transportation in their logarithmic form show intercept and long-term trend. Both variables are not stationary at first level using ADF and PP tests, as shown in Table 2. The results concluded that both series are stationary at their first difference, that is, integrated in order 1, I (1).

\section{Lag length selection}

Table 3 presents the results of the optimal lag selection. The purpose of determining the optimal lag in the VAR model is to eliminate the problem of autocorrelation in the VAR system because lag in endogenous variables in the system of equations will be made as an exogenous variable. The determination of optimal lag can be seen from the value of likelihood ratio (LR), final prediction error (FPE), AIC, Schwarz information criterion (SIC) and Hannan-Quin criterion (HQ).

From the optimum lag results in Table 3, the lag chosen is lag 2. The use of lag 2 as the optimal lag means that all variables influence each other not only in the same period but also in the previous two periods; therefore, the lag is determined as the optimum lag and is used at all stages of the VAR analysis.

\section{Cointegration test}

Cointegration tests are conducted to find out whether there is a balance in the long term between the variables studied, namely, the presence or absence of similarities in movement and stability of relations. Johansen's maximum eigenvalue and trace tests were used to test the presence or absence of cointegration between the variables. The results are presented in Figure 2. The trace statistics reject the null hypotheses of cointegration amongst variables. From the data in Figure 2, it is evident that the values of the trace

\begin{tabular}{|lcccc|}
\hline \multicolumn{5}{|l}{ Unrestricted cointegration rank test (trace) } \\
\hline $\begin{array}{l}\text { Hypothesised } \\
\text { No. of CE(s) }\end{array}$ & Eigenvalue & $\begin{array}{c}\text { Trace } \\
\text { statistic }\end{array}$ & $\begin{array}{c}0.05 \\
\text { Critical value }\end{array}$ & Prob.** \\
None & 0.331679 & 13.98242 & 15.49471 & $0.0834^{*}$ \\
At most 1 & 0.020510 & 0.683858 & 3.841466 & 0.4083 \\
\hline Unrestricted cointegration rank test (maximum eigenvalue) & \\
\hline Hypothesised & Eigenvalue & Max-Eigen & $\mathbf{0 . 0 5}$ & Prob.** \\
No. of CE(s) & \multicolumn{5}{c}{ statistic } & Critical value & \\
None & 0.331679 & 13.29856 & 14.26460 & $0.0706^{*}$ \\
At most 1 & 0.020510 & 0.683858 & 3.841466 & 0.4083 \\
\hline
\end{tabular}

Max-Eigen, maximum eigenvalue; Prob., probability

$*$, No cointegration at $5 \%$ level; $* *$, No co-integration at $1 \%$ level.

FIGURE 2: Johansen-Juselius likelihood cointegration test.

TABLE 3: Optimum lag length selection.

\begin{tabular}{|c|c|c|c|c|c|c|}
\hline Lag & LogL & LR & FPE & AIC & SIC & $\mathrm{HQ}$ \\
\hline 0 & -23.08739 & NA & 0.017298 & 1.618541 & 1.711057 & 1.648699 \\
\hline 1 & 90.69607 & 205.5443 & $1.45 \mathrm{e}-05$ & -5.464262 & -5.186716 & -5.373789 \\
\hline 2 & 97.89723 & $12.07937 \dagger$ & $1.19 \mathrm{e}-05 \dagger$ & $-5.670789 \dagger$ & $-5.208212 \dagger$ & $-5.520000 \dagger$ \\
\hline 3 & 100.5497 & 4.107056 & $1.31 \mathrm{e}-05$ & -5.583852 & -4.936244 & -5.372748 \\
\hline
\end{tabular}

Endogenous variables: $\log (\mathrm{GDP})$ and $\log (\mathrm{TPM})$.

LR, likelihood ratio; FPE, final prediction error; AIC, Akaike information criterion; SIC, Schwarz information criterion; HQ, Hannan-Quin criterion; NA, not applicable/not available.

$\dagger$, Lag order selected by the criterion at $5 \%$ level. 
statistic and maximum eigenvalue are smaller than the critical value at the 5\% significance level. Furthermore, the results of the cointegration test do not find any indication of the probability value that is less than the real level of $5 \%$. The results of the cointegration test above can be interpreted that the two variables used in this study have no long-term relationship. Thus, the Johansen cointegration test suggests that there is no long-run relationship between air transportation and economic growth in the case of Sri Lanka. This implies that a change in logGDP is not co-integrated, which means that a change in logGDP follows a VAR model.

\section{Vector Autoregressive Model}

From several test results that have been performed before, there are stationary variables in the first difference but there is no cointegration in the cointegration test stage. This can be interpreted that the model equation is the VAR estimation model. Variables in a VAR model are decided concurrently and depend more on historical data patterns to establish connections between air transportation and economic growth than economic theories (Bhattarai 2016). The results and insights of vector autoregression are presented in Figure 1-A1.

The focus of this study was to assess the dependency of current values of economic growth and air passenger movements, $\log$ GDP and logTPM on their own past as well as on the past values of other variables. Based on the above results, the unrestricted VAR model with order of two was fitted and the results are presented in Figure 1-A1. In particular, the current value of real economic growth is positively related to its own first lags, negatively related to the second lags and positively related to the first lag of air transportation but negatively related to the second lag of air transportation. On the other hand, the air transportation is positively related to its own first lags, negatively related to its own second lag, negatively related to its first lag of GDP and positively related to the second lag of GDP.

Based on the above discussion, the results of the unrestricted VAR model fitted with significant estimated coefficients of $\log$ GDP and $\log$ TPM are presented in Equations 5 and 6, respectively. Standard errors are shown in parenthesis.

$$
\begin{aligned}
& \log \mathrm{GDP}_{t}=\underset{(0.0509)}{1.335}+1.194 \underset{\left(0.00001^{*}\right)}{\log \mathrm{GDP}_{t}(-1)}-0.134 \underset{(0.4690)}{\log \mathrm{GDP}_{t}}(-2) \\
& -\underset{(0.8827)}{0.0166} \log _{t} \operatorname{TPM}_{t}(-1)-1.465 \underset{(0.1535)}{\log \operatorname{TPM}_{t}(-2)}
\end{aligned}
$$

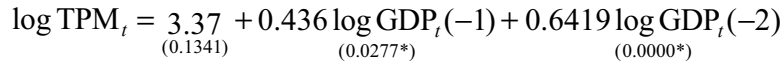

$$
\begin{aligned}
& +0.971 \underset{\left(0.0242^{*}\right)}{\log \operatorname{TPM}_{t}(-1)}-0.384 \underset{\left(0.00021^{*}\right)}{\log \operatorname{TPM}_{t}(-2)}
\end{aligned}
$$

In Equation 5, the estimated coefficients of $\log (\mathrm{GDP})(-1)$ are highly significant at 5\% significance level. It implies that the effect of a unit increase in $\log \mathrm{GDP}(-1)$ whilst keeping other factors constant increases in current logGDP at $1.19 \%$. On the other hand, the past air passenger movement has no effect on the economic growth of Sri Lanka. However, the past economic growth has significant dynamic effect on the current economic growth. The findings show that the economic growth of Sri Lanka has not a significant dynamic relationship with air passenger movement during the study period. The adjusted R-square value for this model is 0.98 , which indicates that $98 \%$ of the variation in the future change in LOG(GDP) observation is explained and shows a high predictive power, with $\mathrm{F}(4.34)=7241, p=0.000$ and $n=34$.

With regard to the model in Equation 6, a two years lag of economic growth has a significant positive impact on air passenger movement, whilst a 1 year lag of economic growth has a significant negative impact on current value of air passenger movement in the study period. On the other hand, the past value of TPMs significantly impacts the current total air passenger movement. The statistically significant positive coefficients of $\log \mathrm{GDP}(-2)$ and $\log (\mathrm{TPM})(-1)$ imply that the effect of a unit increase in $\log (\mathrm{GDP})(-1)$ and $\log (\mathrm{TPM})(-1)$ whilst keeping other factors results constant in a $0.64 \%$ and $0.97 \%$ increase of $\log \left(\mathrm{TPM}_{t}\right)$, respectively, for Sri Lanka. This shows that air transportation of Sri Lanka has a significant dynamic relationship with economic growth and its own lag values during the study period. The adjusted $\mathrm{R}$-square value for this model is 0.98 , which indicates that $98 \%$ of the variation in the future change in LOG(TPM) observation is explained and shows a high predictive power, with F (4.34) = 815.62, $p=0.000$ and $n=34$.

\section{Diagnostic checking}

In empirical research, model specification involves several choices, such as the variables to include, the functional form connecting the variables and the nature of the interaction amongst the variables, if any. However, economic theory normally cannot provide a fitted specification of the dynamic relationships in economic data. This inevitably causes uncertainty with regard to whether the estimated model is correctly specified. This fact motivated the study to conduct the diagnostic tests, such as residual normality, serial correlation and the heteroscedasticity test.

Once a VAR model has been assessed, it is of utmost necessity to see whether the residuals follow the residual assumptions. That is, it is a mandatory requirement to check for the nonexistence of serial correlation and heteroscedasticity and see whether the error term is normally distributed. The BreuschGodfrey test for serial correlation with $p$-values less than 5\% specifies the presence of serial correlation of the residuals. The non-rejection of the null hypothesis of homoscedasticity in case of multivariate autoregressive conditional heteroscedasticity $(\mathrm{ARCH})$ test with $p$-values less than 5\% indicates the presence of heteroscedasticity. A further characterisation of our model includes VAR residual normality test using the orthogonal Cholesky test method for 
the null hypothesis, that is, $\mathrm{H}_{0}$ : residuals that are multivariate normal with $p$-values less than $5 \%$ indicate non-normality.

Table 4 presents the results of diagnostic test carried out in this study, such as serial correlation, heteroscedasticity and normality test.

Firstly, the $\mathrm{ARCH}(\mathrm{LM})$ test was used to test for serial correlation. The results show that the probability of $t$ statistics of LM test is greater than $5 \%$ significance level, indicating that residuals are not serially correlated. Secondly, the Breusch-Pagan test shows that the probability of 0.2091 is greater than $5 \%$ significant value, implying that there is no heteroscedasticity in the residuals. Thirdly, the normality test results show that the probability of 0.6464 is greater than the $5 \%$ significance level, implying that the residuals are normally distributed. Fourthly, the Ramsey resettest for misspecification suggests that there are no misspecifications in the model. Therefore, we fail to reject the null hypothesis of no misspecification. The diagnostic tests results in Table 4 proved that the estimated model is adequate and fulfilled the desired econometric properties. It implies that our model has correct functional form, and its residuals are serially uncorrelated and homoscedastic and normally distributed.

\section{Model stability}

This study used the AR root test to check whether the model is economically expressive and useful. The results of AR root test for two series of joint stationarity with a lag length of 2 are presented in Table 5 .

The results show that the model is economically meaningful and stable. The value of the AR unit root test is 0.977049 less than 1, and all unit roots falling within the unit circle shown in Figure 3 confirm the basic rule of model stability. Therefore, it is derived from these results that there is a dynamic short-term equilibrium relationship between air transportation and economic growth. The established VAR model explains the characteristics of variables in the long term. From the graph in Figure 3, it can be seen that the roots of polynomial characteristics do not lie outside the unit circle.

TABLE 4: Diagnostic tests.

\begin{tabular}{llcc}
\hline Test & Null hypothesis & $t$-Statistics & Probability \\
\hline ARCH(LM) test & No serial correlation & 10.04 & 0.0740 \\
$\begin{array}{l}\text { Breusch-Pagan-Godfrey } \\
\text { test }\end{array}$ & No heteroscedasticity & 13.000906 & 0.2091 \\
Normality test & $\begin{array}{l}\text { There is normal } \\
\text { distribution }\end{array}$ & 0.8724 & 0.6464 \\
Ramsey reset test & No misspecifications & -0.0704801 & 0.4830 \\
\hline
\end{tabular}

Note: $t$-statistics denotes the rejection of null hypothesis at $5 \%$ level.

TABLE 5: Roots of characteristic polynomial.

\begin{tabular}{ll}
\hline Root & Modulus \\
\hline 0.977049 & 0.977049 \\
0.770060 & 0.770060 \\
$0.209211-0.398471 \mathrm{i}$ & 0.450054 \\
$0.209211+0.398471 \mathrm{i}$ & 0.450054 \\
\hline
\end{tabular}

Note: No root lies outside the unit circle. Vector autoregression satisfies the stability condition.
Hence, we can conclude that the estimated model satisfies the stability condition.

Because this study focused on the relationship between air transportation and economic growth, emphasis is placed on the stability of the parameters of estimated VAR. The constancy of the parameters of the VAR is assessed by applying the CUSUM and CUSUMQ plots (Figure 4). As can be seen from the CUSUM plots, there is no movement outside the $5 \%$ critical lines, suggesting that parameters of the estimated VAR models are stable.

\section{Granger's causality test}

In this section, we employ Granger's causality tests on the first differences of LogGDP and LogTPM to determine whether there is a pair-wise causal relationship between these two variables. This process is mostly useful for the standard VAR because it documents temporary causality arising from the lagged coefficients of the

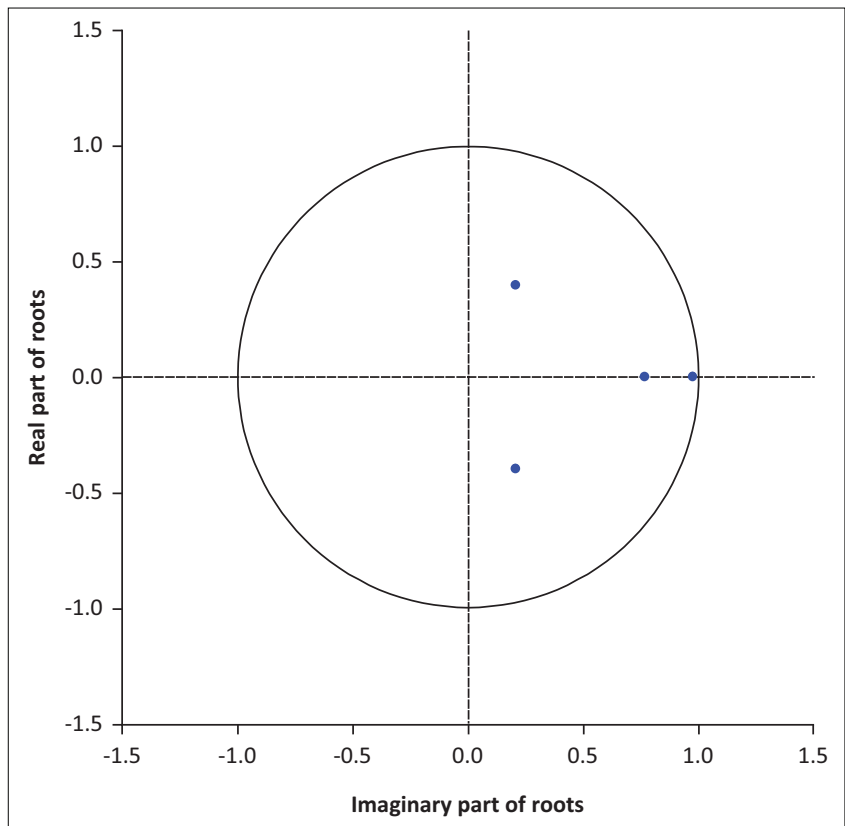

FIGURE 3: Inverse root of autoregressive characteristic polynomial.

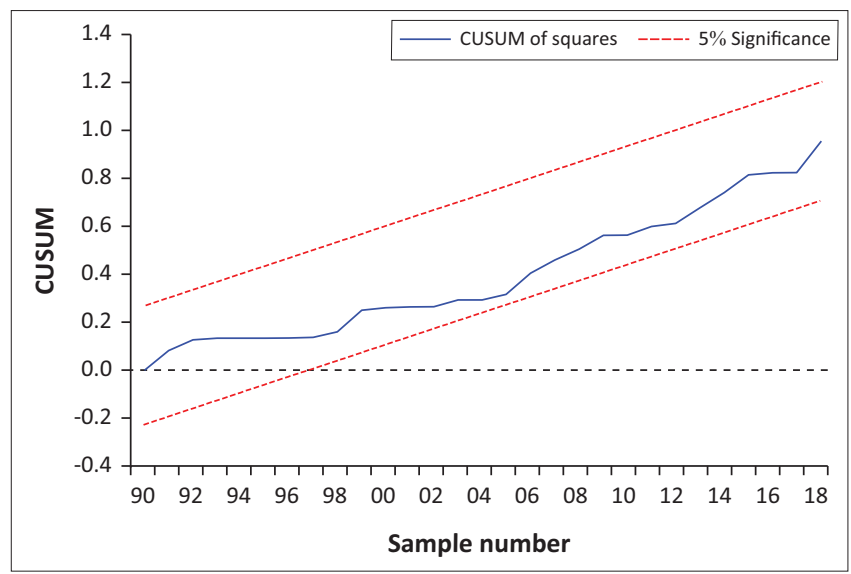

CUSUM, cumulative sum.

FIGURE 4: Cumulative sum of squares plots. 
explanatory differenced variable. It systematically tests for non-zero correlation between the errors of the cause and effect variables. However, the consistency of the output of the Granger's causality test depends on the stationarity of the variables. Table 6 reports the results of multivariate Granger causality tests. The results show that there exists a significant and strong unidirectional causal relationship between economic growth and air transportation, with F-test statistic of 9.63317 and $p$-value of 0000 . On the other hand, we fail to accept the Granger causality from air passenger movement to economic growth in Sri Lanka in the study period.

Table 7 reports the Wald test statistics for multivariate instantaneous causality tests. The null hypothesis GDP does not instantaneously cause air transportation rejected at 5\% significance level, with $p$-values 0.00001 . Similar to the pairwise Granger causality test in Table 6, we fail to accept the instantaneous causality from air transportation to economic growth in Sri Lanka in the study period.

The findings of causality test results indicate that the null hypothesis of this study, that is, the economic growth does not Granger cause air passenger movement, can be rejected, but we cannot reject the null hypothesis that air passenger movement does not Granger cause economic growth. The findings show that there is a unidirectional causality running from economic growth to air transportation, implying that past two years values of economic growth have a predictive capability in explaining the current value of TPMs.

The results of this study are not consistent with those of Brida et al. (2016), Tinoco and Sherman (2014) and Coto-Millán et al. (2013), where the authors found evidence of positive impacts of air transport and airline associations with the local economic growth and development. Moreover, these insights and results are not consistent with those of Chang and Chang (2009), Hu et al. (2015) and Nisansala and Mudunkotuwa (2015), where the authors found a bidirectional causality amongst economic growth and air transport development, and those of Chi and Baek (2013), Fernandes and Rodrigues Pacheco (2010) and Marazzo et al. (2010), where the authors found a unidirectional connection from air transport to

TABLE 6: Vector autoregression Granger causality.

\begin{tabular}{lccc}
\hline Null hypothesis & Obs & F-Statistic & Prob. \\
\hline $\begin{array}{l}\text { LOG(TPM) does not Granger } \\
\text { cause LOG(GDP) }\end{array}$ & 34 & 0.85119 & 0.4377 \\
$\begin{array}{l}\text { LOG(GDP) does not Granger } \\
\text { cause LOG(TPM) }\end{array}$ & - & 9.63317 & $0.0007^{*}$ \\
\hline
\end{tabular}

GDP, gross domestic production; TPM, total passenger movements; Prob., probability. *, Significant at $1 \%$ level.

TABLE 7: Block exogeneity Wald test.

\begin{tabular}{lccc}
\hline Variable & Chi-sq & df & Prob. \\
\hline Dependent variable: LOG(GDP) & & & \\
Excluded LOG(TPM) & 1.702372 & 2 & 0.4269 \\
$\begin{array}{l}\text { Dependent variable: LOG(TPM) } \\
\text { Excluded LOG(GDP) }\end{array}$ & 19.26633 & 2 & $0.0001^{*}$ \\
\hline
\end{tabular}

GDP, gross domestic production; TPM, total passenger movements; Prob., probability. $*$, Significant at $1 \%$ level. economic growth. However, the results of this study are consistent with research conducted by Kasim and Mahmut (2019) where the authors found that there is a causal relationship running from GDP to air transport at the $1 \%$ level of significance for the upper-middle-income countries. The unidirectional causality relationship from GDP to air transportation implies that the growth of economic activity would be advantageous for air transport development. The fact that interconnection from economic development to air travel can be derived suggested that an increase in economy is essential to develop the air transportation sector.

In conclusion, economic growth has the potential to improve the number of passengers carried by the aviation sector in the short run, whilst the interconnection does not run in opposite trend. As evident from the analysis, economic growth holds valuable information to predict air transportation.

\section{Forecasting}

Once a VAR-model has been estimated and the diagnostic tests are fulfilled, the model can be used for forecasting. Apart from forecasts, impulse response analysis and forecast, EVD will be used for investigating the dynamic relationship between air transportation and economic growth. These two forecasting methods simply utilise the past values recursively to get future values.

\section{Impulse response functions}

Impulse response functions were computed for air transportation and economic growth to detect the reaction of the economy to external changes (shocks). Figure 5 demonstrates the impulse response analysis for a fluctuation occurred in period $t$ for a 10-year horizon in a year-by-year approach.

At the start of the forecast, the air transportation slowly declined as a reaction to a shock in economic growth and then develops throughout the forecast horizons. Moreover, the initial response of air transportation to a unit shock in GDP is positive throughout the forecast period. The response of shock to GDP in air transportation, is negative, neutral and irresponsive. This may be attributed to the fact that aviation-led growth is not a feasible strategy to promote economic growth in Sri Lanka. This supports the previous argument that air transportation did not play a significant role in Sri Lanka's real economic growth during 1983-2019. In conclusion, when the overall economic status will rise, the air travel sector will have a significant development.

\section{Forecast error variance decomposition}

Variance decomposition provides information about innovation variables that are relatively more important in vector autoregressive model of order 2 (VAR [2]). This test is used to calculate an estimate of the error variance of a variable, namely, how much the difference between the variables before and after the shock, both the shock itself 


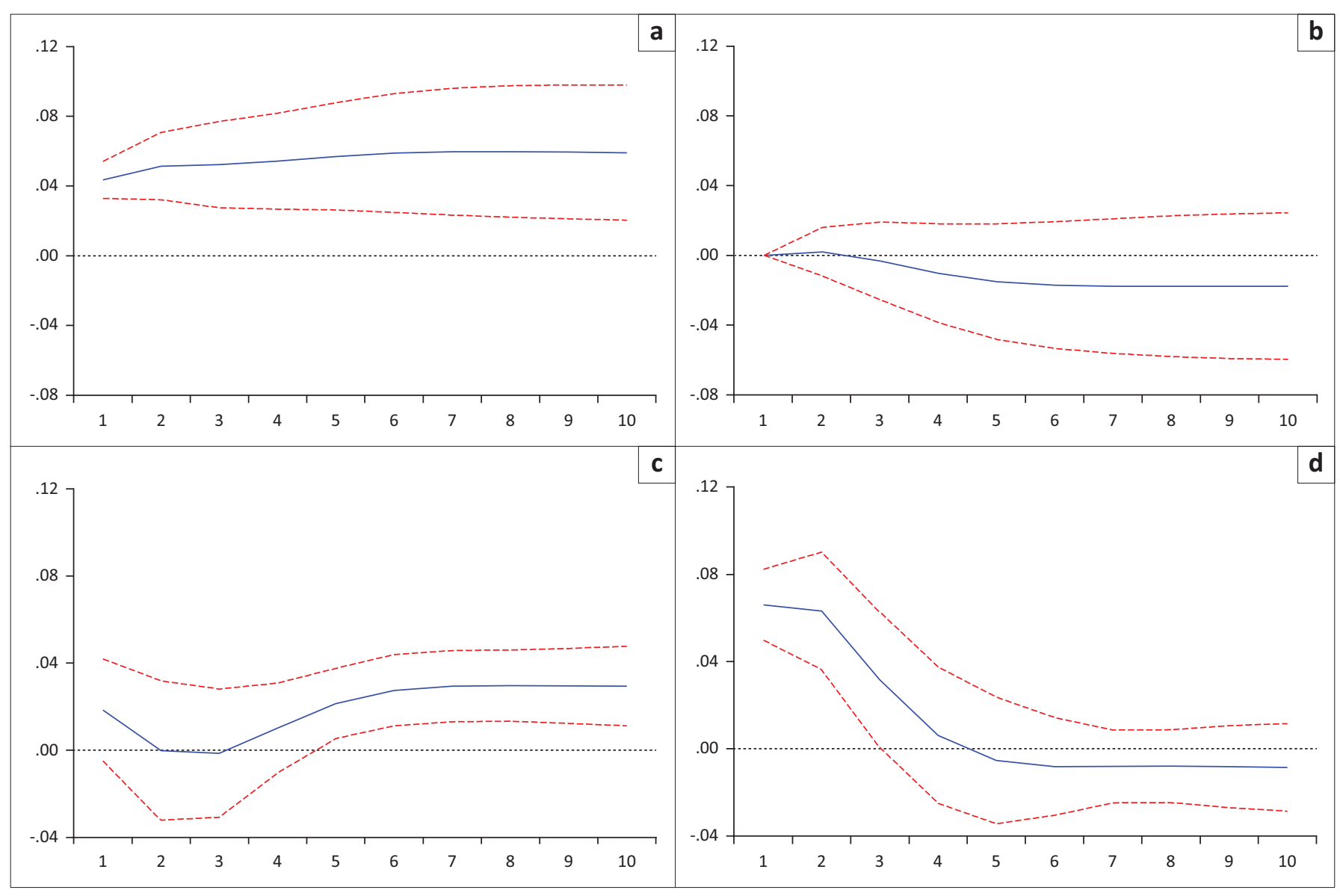

Response to cholesky one S.D. innovations \pm 2 S.E.

$\mathrm{SD}$, standard deviation; SE, standard error.

FIGURE 5: Impulse response functions. (a) Response of LOG(GDP) to LOG(GDP), (b) Response of LOG(GDP) to LOG(TPM), (c) Response of LOG(TPM) to LOG(GDP) and (d) Response of LOG(TPM) to LOG(TPM).

and the shock of other variables. Variance decomposition obtained from VAR system for GDP and TPM is presented in Table 2-A1.

Results in Table 2-A1 illustrate the results of forecast EVD of fitted VAR (2) model using recursive causal ordering logGDP and $\log$ TPM. The first row of Table 2-A1 gives the variance decomposition for logGDP. At short horizons, 99\% of variance is attributed to own shocks; however, at long horizons, shocks in air transportation account for $5 \%$ of the variance. It means that a small fraction of variance is accounted because of air transportation shocks. The second row gives the variance decomposition for logTPM and shows that in short horizons most of the variances of the forecast error are because of own shocks, but in the long horizons import of goods and services shocks account for almost $30 \%$ of the variation. The third row gives the variance decomposition for logTPM. In the short time horizons, $96 \%$ of the variance is because of own shocks, and $34.4 \%$ of the variance is accounted shocks from GDP.

Overall, variation in air transportation has not played a significant role in explaining the dynamic changes in economic growth. In addition, variance decomposition results also showed that air transportation is not a significant indicator accountable for the innovation in real economic growth in Sri Lanka. These findings confirm the results of Granger causality and VAR (2) discussed above.

\section{Conclusion}

The goal of this study is to contribute to the comprehension of the causal relationship between passenger air transport movements and the growth of economy in Sri Lanka. Using Johansen's approach, it was tested whether air transportation and GDP growth are cointegrated. The test signifies that there is no long-run relationship between air transportation and economic growth in the case of Sri Lanka. The VAR model infers that the current economic growth measured as the rate of real GDP is significantly affected by past one lagged values of its own. The effect is positive for one lag of air transportation. Similarly, the current value of air transportation is also positively affected by its own past two lagged values, whilst positively affected by past values of economic growth.

This relationship was analysed from two perspectives. Firstly, given that variables contained in the model are not stationary and presented a unit root, Johansen cointegration techniques were employed to examine the long-term connections between the variables. Secondly, the Granger causality technique was used to examine the causal 
relationship between the variables, which showed that there was no direct causality from air transportation to current economic growth of Sri Lanka as measured by the GDP, whereas economic growth significantly Granger causes air transportation. Empirical results of impulse response function analysis also indicate that shock to air transportation leads to negative response in economic growth, whilst the shock to economic growth leads to positive response in the air transportation. The result also signifies that Sri Lanka cannot enhance its economic growth by improving its air transportation. The variance decomposition analysis shows that shocks to air transportation do not lead to a significant response in economic growth. On the other hand, shocks to economic growth lead to a significant response in air transportation in Sri Lanka. The findings reject the aviationcentric growth hypotheses in the case of Sri Lanka.

This outcome is similar to the situation in European countries including Italy, Ireland, Spain and Portugal, in which the authors proposed that low-income countries show a unidirectional connection from economic growth to air transportation, whilst high-income countries display a bidirectional relationship between air transportation and economic growth. Based on the result of the variance decomposition analysis, the contribution of economic growth to air transportation in the 10th period is $34.4 \%$, whilst the contribution of air transportation to the economic growth is $5 \%$ in the same period. It implies that Sri Lanka can enhance its travel and transport demand by improving its economic performance and economic opportunities.

Policy and management consequences could be derived from the empirical findings. Firstly, this study endorses the idea of the need to prevent restrictions in the economic growth and development in order to enhance the aviation sector. This would lead to an improvement of domestic and foreign investments, as well as the development of economies of scale (Marazzo et al. 2010). Secondly, the current research proposes that sustainable economic growth could not be achieved by promoting air transportation, suggesting a limited role of air transportation policy influencing economic activity. Therefore, policymakers should note that developing the country would have an impact on the development of air transportation. Hence, the focus of the development should be pointed at the transportation industry itself. In order for air transportation to impact the economic development in Sri Lanka, the air transport industry should be stimulated by considering its spillover effect as well as the provision of supporting government policies. In future studies, researchers should endeavour to utilise panel data and cover longer study duration by using other variables, such as tourism, trade and investment.

\section{Acknowledgements}

The authors would like to thank Dr D.M.R. Dissanayake, senior lecturer, Faculty of Commerce and Management Studies at the University of Kelaniya for his insightful comments. They are also thankful to the Faculty of Graduate Studies at the University of Kelaniya for giving them necessary guidance for awarding publication charges.

\section{Competing interests}

The authors have declared that no competing interests exist.

\section{Authors' contributions}

Both authors contributed equally to this work.

\section{Funding information}

This research received no specific grant from any funding agency in the public, commercial or not-for-profit sectors.

\section{Data availability statement}

Data sharing is not applicable to this article as no new data were created or analysed in this study.

\section{Disclaimer}

The views and opinions expressed in this article are those of the authors and do not necessarily reflect the official policy or position of any affiliated agency of the authors.

\section{References}

Anfofum, A.A., Saheed, S. \& Iluno, C., 2015, 'Air Transportation Development and Economic Growth in Nigeria', Journal of Economics and Sustainable Development 6, 1-11.

Bourguignon, F. \& Darpeix, P.-E., 2016, Air traffic and economic growth: The case of developing countries, Working Paper NO- 09, Paris School of Economics, Paris.

Bhattarai, K., 2016, 'Growth and income distributions $\mathrm{n}$ four EU economies', international Advances in Economic Research 22(3), 263-277. https://doi. org/10.1007/s11294-016-9594-8

Baker, D., Merkert, R. \& Kamruzzaman, M., 2016, 'Regional aviation and economic growth: Cointegration and causality analysis in Australia', Journal of Transport Geography 43(2015), 140-150. https://doi.org/10.1016/j.jtrangeo.2015.02.001

Brida, J.G., Fasone, V., Scuderi, R. \& Zapata, S., 2014, 'Research note: exploring the determinants of cruise passengers' expenditure at ports of call in Uruguay', Tourism Economics 20(5), 1133-1143. https://doi.org/10.5367/te.2013.0322

Brida, J.G., Rodríguez-Brindis, M.A. \& Zapata-Aguirre, S., 2016, 'Causality between economic growth and air transport expansion: Empirical evidence from Mexico', World Review of Intermodal Transportation Research 6(1), 1-15.

Chang, Y.H. \& Chang, Y.W., 2009, 'Air cargo expansion and economic growth: Finding the empirical link', Journal of Air Transport Management 15(5), 264-265. https:// doi.org/10.1016/j.jairtraman.2008.09.016

Chi, J. \& Baek, J., 2013, 'Dynamic relationship between air transport demand and economic growth in the United States: A new look', Transport Policy 29, 257-260. https://doi.org/10.1016/j.tranpol.2013.03.005

Coto-Millán, P., Agüeros, M., Casares-Hontañón, P. \& Pesquera, M.A., 2013, 'Impact of logistics performance on world economic growth (2007-2012)', World Review of Intermodal Transportation Research 4(4), 300-310.

Engle, R. \& Granger, C., 1987, 'Cointegration and error correction: Presentation, estimation and testing', Econometrica 55(2), 251-276. https://doi.org/10.2307/1913236

Fernandes, E. \& Rodrigues Pacheco, R., 2010, 'The causal relationship between GDP and domestic air passenger traffic in Brazil', Transportation Planning and Technology 33(7), 569-581. https://doi.org/10.1080/03081060.2010.512217

Granger, C.W.J. \& Joyeux, R., 1980, 'An introduction to long-range time series models and fractional differencing', Journal of Time Series Analysis 1(1), 15-29. https:// doi.org/10.1111/j.1467-9892.1980.tb00297.x

Gujarati, D.N., 2004, Basic econometrics, 4th edn., McGraw-Hill.

Hakim, M.M. \& Merkert, R., 2016, 'The causal relationship between air transport and economic growth: Empirical evidence from South Asia, Journal of Transport Geography 56, 120-127. https://doi.org/10.1016/j.jtrangeo.2016.09.006

Hansen, H. \& Johansen S., 1993, Recursive estimation in cointegrated var-models, Working Paper, Institute of Mathematical Statistics, University Of Copenhagen.

Hansen, H. \& Johansen S., 1999, 'Some tests for parameter constancy in cointegrated var-models', Econometrics Journal 2(2), 306-333. https://doi.org/10.1111/1368423X.00035

Hu, Y., Xiao, J., Deng, Y. \& Xiao, Y., 2015, 'Domestic air passenger traffic and economic growth in China: Evidence from heterogeneous panel models', Journal of Air Transport Management 42, 95-100. https://doi.org/10.1016/J.Jairtraman. 2014.09.003 
Johansen, S., 1988, 'Statistical analysis of cointegration vectors', Journal of Economic Dynamics and Control 12, 231-254. https://doi.org/10.1016/0165-1889 (88) $90041-3$

Johansen, S., 1995, Likelihood-based inference in cointegrated vector autoregressive models, advanced texts in econometrics, Oxford University Press, Oxford.

Kasim, K. \& Mahmut, B., 2019, Causal relationship between air transport and economic growth: Evidence from panel data for high, upper-middle, lower-middle and low-income countries', Journal of Humanities and Social Sciences 22(3), 24-43. https://doi.org/10.5782/2223-2621.2019.22.3.24

Marazzo, M., Scherre, R. \& Fernandes, E., 2010, 'Air transport demand and economic growth in Brazil: A time series analysis', Transportation Research 46, 261-269. https://doi.org/10.1016/j.tre.2009.08.008

Mehmood, B., Khan, A. \& Khan, A., 2012, 'Empirical scrutiny of demographic dividend of economic growth: Time series evidence from Pakistan', Romanian Review of Social Sciences 2, 3-11.
Mehmood, B. \& Kiani, K., 2013, 'An inquiry into nexus between demand for aviation and economic growth in Pakistan', Academicia 3(10), 200-211.

Nisansala, N. \& Mudunkotuwa, M., 2015, 'A multivariate co-integration analysis of air passenger movement: Empirical evidence from in Sri Lanka', in 8th International Research Conference, 2015 Sri Lanka, General Sir John Kotelawala Defense University, pp. 275-282, viewed 18 July 2018, from http://Ir.Kdu.Ac.Lk/Handle/345/1558.

Stock, J.H. \& Watson, M.W., 1993, 'A simple estimator of cointegrating vectors in higher order integrated systems', Econometrica 61(4), 783-820. https://doi. org $/ 10.2307 / 2951763$

Tinoco, J.K. \& Sherman, B.W., 2014, 'Something old is new again: airline-airport Consortia and key stakeholder benefits', World Review of Intermodal Transportation Research 5(1), 1-17.

World Bank Report, 2018, viewed 13 October 2018, from http://Documents.Worldbank. Org/Curated/En/716781571813265877/Pdf/Air-Transport-Annual-Report-2018. Pdf. 


\section{Appendix 1}

TABLE 1-A1: Correlation analysis.

\begin{tabular}{lll}
\hline Variable name & $\log ($ GDP $)$ & $\log (T P M)$ \\
\hline $\log ($ GDP $)$ & 1 & 0.9859 \\
$\log ($ TPM $)$ & 0.9859 & 1 \\
\hline
\end{tabular}

GDP, gross domestic production; TPM, total passenger movements.

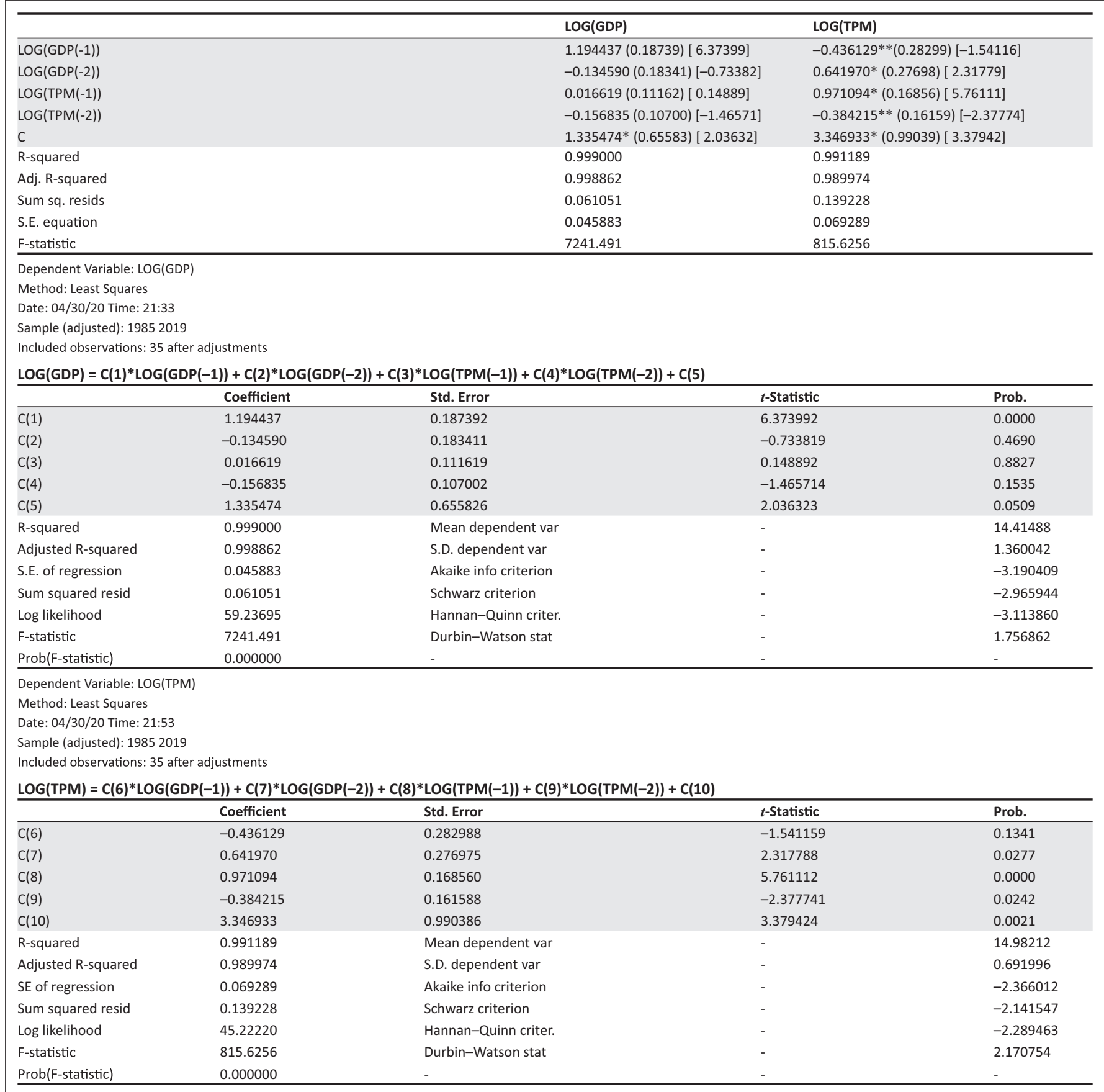

GDP, gross domestic production; TPM, total passenger movements; Sum sq. resids, sum of squared residuals; SE, standard error.

$*$ and ${ }^{* *}$, indicate significance at $1 \%$ and $5 \%$ levels.

Standard errors are in ( ) and $t$-statistics in [ ].

FIGURE 1-A1: Vector autoregressive model. 
TABLE 2-A1: Variance decomposition.

\begin{tabular}{|c|c|c|c|}
\hline Period & SE & LOG(GDP) & LOG(TPM) \\
\hline \multicolumn{4}{|c|}{ Variance decomposition of LOG(GDP) } \\
\hline 1 & 0.043426 & 100.0000 & 0.000000 \\
\hline 2 & 0.067302 & 99.91025 & 0.089753 \\
\hline 3 & 0.085232 & 99.79589 & 0.204109 \\
\hline 4 & 0.101536 & 98.80888 & 1.191120 \\
\hline 5 & 0.117385 & 97.43975 & 2.560249 \\
\hline 6 & 0.132439 & 96.29741 & 3.702593 \\
\hline 7 & 0.146336 & 95.49470 & 4.505299 \\
\hline 8 & 0.159041 & 94.93473 & 5.065274 \\
\hline 9 & 0.170704 & 94.52145 & 5.478554 \\
\hline \multicolumn{4}{|c|}{ Variance decomposition of LOG(TPM) } \\
\hline 1 & 0.068546 & 7.257041 & 92.74296 \\
\hline 2 & 0.093248 & 3.922137 & 96.07786 \\
\hline 3 & 0.098487 & 3.537269 & 96.46273 \\
\hline 4 & 0.099194 & 4.526518 & 95.47348 \\
\hline 5 & 0.101617 & 8.742104 & 91.25790 \\
\hline 6 & 0.105572 & 14.85053 & 85.14947 \\
\hline 7 & 0.109886 & 20.85453 & 79.14547 \\
\hline 8 & 0.114082 & 26.07400 & 73.92600 \\
\hline 9 & 0.118114 & 30.54302 & 69.45698 \\
\hline 10 & 0.122015 & 34.41839 & 65.58161 \\
\hline
\end{tabular}

GDP, gross domestic production; TPM, total passenger movements; SE, standard error. 